\title{
O ISOLAMENTO E OS IMPASSES DOS PROCESSOS REPRESENTACIONAIS EM MACEIÓ
}

\section{BARROS, R. R. DE A. SOLITÁRIOS NO PARAÍSO: PRODUÇÃO CULTURAL E EXPRESSÕES DE ISOLAMENTO EM MACEIÓ. MACEIÓ: FAPEAL: IMPRESSA OFICIAL GRACILIANO RAMOS, 2018.}

\section{LUÍZ FERNANDO BARBOSA GOMES MAGALHÃES ${ }^{1}$}

\section{RESUMO}

Em "Solitários no paraíso", Rachel Barros desvela a teia de processos que se organizam ao redor da ideia isolamento, um comportamento identificado como causador de um mal-estar reiterado, presente nos discursos do ambiente cultural maceioense. Este é operacionalizado a partir de relações nomeadas como de "alheamento", "exterioridade" e "generalidade", elementos que instituem a base social da cognição e orientam as formas de expressão cultural na cidade. Esta construção é apresentada através de uma formação cultural que se confunde com a estruturação do território de Maceió e de Alagoas. Para elucidar os caminhos que se entrecruzaram nesta configuração, são mobilizados um múltiplo conjunto de fontes, convergindo etnografia, dados quantitativos, estudos históricos, geográficos, cartas de viajantes, obras literárias, material publicitário e jornalístico. Esta resenha evidencia os argumentos elaborados pela autora para explicar a dinâmica do isolamento, destacando os impasses que emergem nos processos de definição dos elementos de representação desta cultura.

\section{PALAVRAS-CHAVE}

Representações sociais; Cultura alagoana; Produção cultural; Cultura do isolamento; Maceió.

${ }^{1}$ Doutorando do Programa de Pós-Graduação em Sociologia da Universidade Federal de Pernambuco (PPGS/UFPE). 
Me lembro com clareza dos primeiros momentos em que o tema da cultura alagoana me suscitou questionamentos mais consistentes. Na ocasião, ao iniciar reflexões e diálogos sobre "identidade alagoana" várias vezes me deparei com a indicação da produção de Rachel Barros sobre o tema. Seu nome aparecia em matérias de jornais, orbitava os projetos editoriais publicados sobre autores alagoanos e sempre despontava como alguém com quem que eu precisava conversar para me aprofundar e conhecer fontes de pesquisa nesta direção. Porventura, um dia me deparei com ela e, numa breve conversa, consegui algumas indicações de leitura. Além disso, fui informado que ela possuía um texto sobre o tema, entretanto estava escrita em francês. O trabalho foi o resultado do seu doutorado em Antropologia e Etnologia Social na École des Hautes Études en Sciences Sociales. Minha limitação de tradução, no entanto, me impediu assimilar suas contribuições para a pesquisa que estava em curso.

No final de 2018, mais de uma década após sua elaboração original, o texto obteve uma tradução e foi publicado pela Fundação de Amparo à Pesquisa do Estado de Alagoas (FAPEAL) em parceria com a Imprensa Oficial Graciliano Ramos, não à toa, na Coleção Alagoas Bicentenário, por ocasião da comemoração dos 200 anos de Emancipação Política de Alagoas.

Em "Solitários no paraíso: produção cultural e expressões de isolamento em Maceió" (2018) a autora desvela a complexa teia de processos e narrativas que se organizam ao redor da ideia isolamento, um habitus (BOURDIEU, 2002; ELIAS, 1997) incorporado e reproduzido no espaço social maceioense que é tributário do isolamento social dos seus indivíduos e grupos constituídos. Um comportamento identificado na pesquisa como causador de um mal-estar reiterado, presente através de diversas formas, nos discursos do ambiente cultural da cidade: desde aqueles relacionados à baixa circularidade dos produtos e serviços culturais ofertados, a angústia daqueles que empreendem iniciativas no setor e se veem repetidamente sozinhos em seus esforços, como também, numa espécie de "tropical melancolia" na qual estes maceioenses vivem mergulhados.

Segundo a autora, este isolamento se manifesta contemporaneamente de diversos modos, mas está expresso, por exemplo, na escolha e perpetuação do slogan turístico "Maceió, paraíso das águas". Este é operacionalizado a partir de relações nomeadas pela autora como de "alheamento", "exterioridade" e "generalidade", elementos que instituem a base social da cognição, orientando as formas de expressão cultural na cidade. Eles explicam, por exemplo, os impasses que emergem em processos de definição de elementos de (auto)representação nesta cultura, pois, ao esvaziarem as fontes inspiradoras advindas da vida coletiva/compartilhada, fazem com que o elemento natural se manifeste como única alternativa para tal. 
Esta construção cultural, entretanto, é apresentada por Rachel Barros através de uma formação que se confunde não só com a estruturação do território de Maceió, mas, entrelaça-se a própria história de composição do Estado de Alagoas. Para elucidar os caminhos que se entrecruzaram nesta configuração, a autora mobiliza um conjunto de fontes, convergindo métodos etnográficos, dados quantitativos, estudos históricos, geográficos, crônicas de diversos períodos, cartas de viajantes, obras literárias, material publicitário e jornalístico.

A obra é organizada em seis capítulos. O primeiro, uma introdução, intitulado “O isolamento como tema" apresenta de forma breve os principais argumentos abordados, norteando o leitor diante das complexas conexões estabelecidas para explicar a emergência do fenômeno do isolamento. Os capítulos subsequentes estão divididos não apenas através de diferenciações temáticas, mas também, estão relacionados, respectivamente, a períodos distintos deste encadeamento.

Em "Aspectos de uma pedagogia exemplar" a autora destaca o modus operandi devastador ostentado pela empresa civilizatória europeia neste território. Uma dinâmica de extermínio que foi interpretada pela historiografia alagoana como um aspecto demarcador desse lugar, atribuindo-o uma dimensão mítica. Um processo iniciado como uma estratégia de garantia da posse das terras através do aniquilamento da população indígena autóctone, fato que se torna evidente especialmente no processo de extermínio dos caetés, mas que se estende, em seguida, aos índios potyguaras.

Uma dinâmica que se inscreve numa relação predatória com as abundantes matas e florestas alagoanas, encadeamento que é anunciado pela autora em sua extensa dimensão através de "narrativas da devastação": dados, registros históricos, documentos e relatórios do período que relatam tanto a identificação das matas como provedoras de uma madeira de qualidade exemplar, como a transferência das áreas de extração conforme o avanço do desmatamento - trabalho que em 1799 passou a ser, inclusive, supervisionado por um "conservador das matas", cargo criado primitivamente no território alagoano para lidar com o extenso estrago conduzido. Uma prática que não se restringiu a extração da madeira, mas que teve continuidade com o avanço da "civilização canavieira" e que a marcou culturalmente, se perpetuou numa espécie de aversão às matas, algo que está conectado, por exemplo, a ausência da caça na tradição culinária do universo dos engenhos.

Essas matas ocupam um lugar central na história e cultura alagoana. A obra traz um trecho de uma entrevista realizada com o historiador Luiz Sávio de Almeida sobre a questão e reconhece-as não como um mero cenário, mas como uma personagem da história alagoana, uma protagonista deste universo simbólico que inspira o rico imaginário popular e que servem de 
esteio para duas interpretações canônicas (ALMEIDA, 2008; LINDOSO, 2005) da produção intelectual e tensionamentos sobre a etnicidade (POUTIGNAT, STREIFF-FENART, 1997) alagoana. Deste modo, por várias razões, ao longo da formação deste Estado, as matas se configuraram como "um inimigo a vencer para os que não conheciam sua geografia e os perigos daquele território quase virgem" (BARROS, 2018, p.49), precisavam também ser "aniquiladas", pois, abrigaram as duas maiores iniciativas de organização política e expressão cultural que se tornaram referencias estruturantes de resistência, respectivamente: o domínio de Palmares e as lutas dos Cabanos.

Na seção seguinte da obra, "Maceió, uma urbanização tardia", a autora irá apresentar, a partir da dimensão histórica do processo de formação de Alagoas, o ambiente político e as disputas entre as elites que culminaram com ascensão e transferência da capital para Maceió, as peculiaridades do seu processo de urbanização e as mais evidentes consequências desse na formação do comportamento de isolamento. Esta narrativa é conduzida pela caracterização de Maceió como uma cidade com ares rurais, onde a herança cultural advinda do domínio do açúcar se impõe no espaço urbano nascente por diversas vias, mantendo sua influência econômica, política e simbólica, ainda que num contexto distinto.

Essa peculiaridade marcou profundamente o ambiente político de Maceió, caracterizado pela persistência de resoluções violentas de divergências e por um insistente tom de "arrogância agrária" e mandonismo. Um tipo de violência que chama a atenção da autora pelo seu caráter singular com relação a outras cidades grandes e médias do brasil, assinalado por sua sutileza, uma didática brutal, uma pedagogia do "fazer calar". Uma dinâmica que delimitou rígidas fronteiras para a população negra liberta no início do século XX, e que também, determinou a produção intelectual sobre essa presença na cidade, que se manteve, em sua grande maioria, genérica e lacônica, limitando-se a breves relatos sobre as ocupações comerciais da comunidade negra no contexto em questão.

Esta narrativa historiográfica fundamentada na origem rural e canavieira da cidade de Maceió é apontada pela autora como uma tese tradicional e comumente legitimada nos círculos intelectuais do Estado. No entanto, ela apresenta também outras vias para estruturação de um mito de origem para a cidade, como a contestação que vem sendo conduzida pelo historiador Moacir Sant'Ana, que defende o surgimento da cidade a partir de um núcleo de pescadores, mas também, aponta para uma narrativa que se inscreve no âmbito de um "Nordeste Marítimo". Apontando para uma série de dados e relatos historiográficos relacionados à crise do açúcar e debandada dos engenhos, a autora defende a predominância das relações comercias na 
organização econômica da cidade no período, fato que reflete em uma estrutura de classes menos rígida e mais diversificada, contradizendo, portanto, a tradição historiográfica clássica².

O processo de urbanização de Maceió é caracterizado também pelos seus aspectos arquitetônicos. Utilizando como exemplo a disseminação de residências inspiradas no formato dos bangalôs europeus nas primeiras décadas do século XX, Barros (2018) expõe a atração do maceioense por aquilo que é "de fora" e o seu desinteresse pelo regional, diga-se de passagem, num período em que o Nordeste experienciava o crescimento do Movimento Regionalista e se observava um processo de valorização do homem nordestino e da sua cultura desatrelada da herança academicista - uma prática que, como veremos se repete na vida em Maceió, fato que a autora aborda mais atentamente na última parte do livro.

Esta configuração resultará num ambiente intelectual que é apresentado pela autora nessa primeira metade do século XX como "acanhado" - apresentando, uma série de relatos depreciativos de historiadores acerca da ausência de espaços educacionais minimamente estruturados e da impossibilidade de vivenciar uma vida intelectual neste contexto. É a partir deste panorama que é introduzido o tema da fuga dos intelectuais, fundamentando seus argumentos, especialmente, a partir da obra "Maceió Medúsica" (2015) de Arrisete Costa. Apresentando estas narrativas de auto-depreciação dos intelectuais alagoanos e conectando-as ao mal-estar que atravessa o século, a autora sublinha a disseminação de imagens do fracasso entre frases banais encontradas na literatura e nas falas dos alagoanos. Estes fatores levam-na рага uma interpretação sobre o que descreve como uma ausência de lugar coletivo de identificação, fruto da indisponibilidade de símbolos e práticas "de dentro" que possam ser tomados como referências coletivas - um dos fatores estruturantes do isolamento da produção cultural do século.

Já em "Do inferno de lama ao paraíso das águas", Barros (2018) reflete sobre a profunda transformação que a "paisagem natural" maceioense sofre ao longo dos séculos XIX e XX. Assim, a partir de relatos encontrados na produção escrita - especialmente, historiográfica, geográfica e ficção literária - ilustra sua passagem de uma imagem preponderantemente negativa e depreciativa para uma percepção positivada da mesma. Para tal, a autora lança mão de um aporte teórico - com destaque para as contribuições de Augustin Berque (1994) -, que possibilita tomar a paisagem como uma entidade dinâmica e interpretada, constituída por uma série de processos interacionais e fruto de esforços representacionais.

\footnotetext{
2 É importante frisar que a obra original foi escrita antes da produção da pesquisa conduzida por Isadora Padilha em "Levada à Margem" (2012), que defende, ainda, outras matrizes para o processo de urbanização de Maceió, também ligados aos fluxos comerciais, mas, que aponta para a importância específica do bairro da Levada neste encadeamento.
} 
Esses relatos apresentam esta paisagem, como uma "natureza hostil e maldita". As praias, eram vistas como áreas inseguras, desabitadas e perigosas. As lagoas aparecem nos textos de Octávio Brandão como o lugar do proibido e do interdito, e em relatórios como imersas em um imaginário mórbido e adoecido, ilustrado por pântanos e mangues alagadiços. A Insalubridade dos rios foi tema de uma série de reflexões Manuel Diégues Jr. Em síntese, estas águas eram comumente interpretadas em sua influência maléfica, como transmissoras de moléstias e "atraso". No entanto, Rachel Barros (2018) apresenta uma série de sensíveis transformações que ocorreram sobre esta paisagem, informa, por exemplo, que as percepções sobre as lagoas começam a mudar com a assimilação de uma série de discursos e iniciativas ecológicas, como o Movimento Pela Vida nos anos 80, mas, define que a transformação desta paisagem natural como um todo repousa efetivamente sob o advento do turismo nas últimas décadas do século XX. A partir do crescimento do setor e da implementação de uma série de políticas públicas e privadas de promoção desta paisagem, o território litorâneo da cidade se tornou o espaço mais cobiçado pela especulação imobiliária.

Este panorama dá outro sentido ao imaginário das águas entre os maceioenses. Torna evidente as condições de possibilidade que permitiram que a conceituação de Dirceu Lindoso sobre a anfibiedade de Alagoas e a preponderância do elemento natural na elaboração de imagens representativas do lugar se disseminassem de tal modo. Contudo, a metáfora insular mobilizada por Lindoso para descrever essa cultura, é utilizada pela autora em sua ambivalência para articular a ideia de isolamento e para simbolizar as dificuldades dos maceioenses em estabelecer uma ancoragem simbólica "sobre outras margens", no caso, da história e da cultura popular, argumento que é desenvolvido na seção seguinte da obra: "Condenados ao paraíso".

A partir dos anos 1970 a atividade turística passou a mobilizar continuamente os elementos naturais da paisagem litorânea, um processo que reverberou intensamente em diversos espaços, seja na publicidade oficial, na economia e comércio local, como também nos equipamentos e monumentos públicos do construídos período. A autora salienta, entretanto, que a predominância desse elemento natural no argumento turístico da cidade como algo que encobre o alheamento do maceioense com a história e o seu desligamento simbólico e afetivo diante outras referências locais.

Ao longo do texto, a autora ilustra o desenvolvimento da invenção da orla marítima de Maceió entre os anos 1970 e 1990, articulando-o ao crescimento do mercado imobiliário em direção às regiões praieiras, a instalação dos hotéis e a difusão dos negócios voltados para o turismo. Um esforço que conectou e mobilizou uma série de agentes estatais e de mercado, na medida em que a pauta foi assimilada pela estrutura estatal e passou a ser continuamente 
narrada pela imprensa local. Esta profusão de ações resultou não apenas no crescimento vertiginoso do fluxo turístico local, mas também na galvanização do slogan "Maceió, paraíso das águas", assim como, de sua passagem para uma escala superior, provocando a proliferação da expressão: "Alagoas, Paraíso das águas".

Com a elevação do prestígio da orla nos anos 1990, uma série de atividades que anteriormente eram realizadas em outros espaços da cidade, foram atraídas para esse território, agregando uma série de novas atribuições ao mesmo. Os folguedos, que desde o final dos anos 1980 já se apresentavam periodicamente para o público turístico, passaram a ocupá-la com frequência. Migraram para lá também as comemorações cívicas municipais e estaduais, os concursos de bumba-meu-boi, os desfiles de blocos carnavalescos, as paradas militares e, também, uma série de ações voltadas para educação da população. Entretanto, a autora observa que um dos componentes do mercado turístico local já apresentava sinais de uma problemática de difícil resolução. Os suvenires vendidos nos mercados de artesanato apresentavam fácies genéricas, advindos de Estados vizinhos, limitavam suas referências aos elementos de natureza marítima, conservando-se distante das representações da cultura popular que comumente abundam as feiras de artesanatos de outros polos turísticos, fato que revelava o distanciamento dos artesãos do interior, uma configuração que demonstrava a inabilidade dos poderes públicos na articulação destes mercados criativos.

Na medida em que se dilatavam os mercados turísticos, iniciam-se uma série de articulações para interiorização do turismo em Alagoas. Os primeiros materiais publicitários divulgados nesse sentido, entretanto, continuavam a apresentar uma lógica onde argumento natural predominava, apesar da diversificação dos potenciais e da ausência de paisagens "paradisíacas" dos municípios no interior. Pensado como uma alternativa para tal, o turismo cultural surge como uma resposta para a matização deste mercado. No esteio desses esforços "o passado" invade o presente maceioense de uma maneira até ali inédita. Se assomam ações de valorização de eventos memoriosos e de personagens políticos, intelectuais e empresários locais, de singularidades históricas capazes de atrair públicos. Em resumo, observa-se uma ampliação do espaço do cultural no âmbito do turismo e dos seus reflexos na imprensa e mercado editorial. Рara a autora, entretanto, este movimento de valorização se limita a uma espécie de "empreendimento de fachada", mobilizando uma série de relatos que apontam tanto para a superficialidade das políticas implementadas, quanto para a persistência das referências simbólicas de sol e mar nos frutos deste processo: "Mesmo quando o produto a ser divulgado não é a praia, esta aparece ao menos como coadjuvante do espetáculo produtivo" (BARROS, 2018, p.192), conformando uma representação que "aprisiona" a imaginário alagoano. 
O isolamento é, em seguida, analisado pela autora no contexto da fabricação de dois símbolos oficiais. Primeiramente, se manifesta nas contendas ao redor da escolha do brasão da bandeira de Alagoas, momento no qual emerge a proposição da inserção do "Gogó da Ema" na composição heráldica do brasão, onde se apresenta a justificativa de sua história como primeiro símbolo turístico de Maceió, mas que é rejeitada por ser "efêmero". E, de maneira similar, na realização do concurso para a escolha da marca turística da Empresa de Turismo de Maceió em 1995, onde apesar da proposta vencedora ter sido a que trazia um sururu, foi acusada de ser "específica demais" e acabou dando lugar a uma imagem de um coqueiro de óculos escuros. Ambos os debates remetem às operações que estão diretamente relacionadas ao comportamento de isolamento. A autora delineia que os elementos representacionais mobilizados nos exemplos são ambos, evidentemente naturais, mas sobre estes opera-se outro processo, estas escolhas sempre privilegiam imagens genéricas, em detrimento daquelas particularizantes. Рara a autora, esta é uma lógica que se articula institucionalmente e produz um contexto guiado pelo desligamento para com outras referências locais, resumidamente: "Alheamento, Exterioridade e Generalidade, portanto, são princípios fundamentais da lógica institucional que se manifesta nos produtos, bem como nos discursos" (BARROS, 2018, p.208).

Na última parte da obra, intitulada "Os solitários no paraíso", Rachel Barros apresenta suas considerações finais sobre o tema, remontando brevemente os argumentos desenvolvidos ao longo do texto e levantando novas questões, sem necessariamente responde-las. Discorre sobre como o desenvolvimento do comportamento de isolamento está relacionado a dificuldade do "festejar com convicção" as imagens coletivas da história local, o que por sua vez, denuncia a ausência de uma memória ritual e a escassez de mediadores sociais capazes de promover a circularidade dos símbolos de autoreconhecimento local. A natureza e a paisagem, por sua vez, segundo ela, acabam por ocupar um lugar "vazio de história". Por isso, ainda que se possa observar a emergência do fenômeno do turismo cultural no início do século XXI, a memória social que the é correlata surge como uma espécie de "metáfora jardineira", isto é, "de implantação recente e, num certo sentido, artificializada por seu caráter altamente indutivo" (BARROS, 2018, p.213). A este mesmo processo, entretanto, a autora conecta a dificuldade dos símbolos étnicos oriundos do universo afro-brasileiro de serem alçados a lugares de prestígio e representação mais simbolicamente amplos e englobantes - uma condição que, em certa medida, como uma série de pesquisas recentes tem demonstrado (AMORIM, 2019; LIMA, 2015; MAGALHÃES, 2016), já apresenta evidentes sinais de mudança, o que me faz refletir sobre a atual configuração deste cenário identitário como um todo, suas transformações mais recentes 
e a pertinência do tom pessimista da obra quanto ao desenvolvimento destes processos no futuro.

"Solitários no paraíso" condensa de maneira extraordinária temas estruturantes do universo intelectual da cultura alagoana, realizando conexões inéditas entre as múltiplas contribuições que mobiliza para a construção de suas teses centrais. A riqueza dos dados e das fontes que ostenta, juntamente com as diversas "portas" que abre ao revolver e questionar interpretações canônicas da historiografia alagoana, não só denunciam o cunho intergeracional da produção do conhecimento do qual a autora é herdeira, mas evidencia o caráter de indispensabilidade da obra para todos aqueles que querem se aventurar pelo tema. Ainda assim, mesmo que não prejudique seu conteúdo, surpreende a quantidade de problemas de revisão que se alastram ao longo do texto - por isso, espero, sinceramente, que uma nova edição do mesmo não fique por aguardar uma nova publicação por mais uma década.

\section{REFERÊNCIAS}

ALMEIDA, L. S. de. Memorial biográfico de Vicente de Paula, o capitão de todas as matas: guerrilha e sociedade alternativa na mata alagoana. Maceió: Edufal, 2008.

AMORIM, A. N. S. Alagoanidade em questão: Notas para uma sociogênese da moderna tradição de narrativas e narradores da identidade alagoana. Dissertação de mestrado defendida junto ao Programa de Pós-graduação em Sociologia da Universidade Federal de Alagoas. Ano de defesa: 2019.

BARROS, R. R. de A. Solitários no paraíso: produção cultural e expressões de isolamento em Maceió. Maceió: Fapeal: Impressa Oficial Graciliano Ramos, 2018.

BERQUE, A. Cinco proposições para uma teoria da paisagem. Paris: Editora Champ, 1994.

BOURDIEU, P. Esboço de uma teoria da prática: precedido de três estudos de etnologia cabila. Oieiras: Celta, 2002.

COSTA, A.C. L. Maceíó Medúsica: Uma interpretação histórica das imagens da diáspora de intelectuais alagoanos na literatura - 1930/40. Maceió: Edufal, 2015.

ELIAS, N. Os alemães:a luta pelo poder e a formação do habitus nos séculos XIX e XX. Rio de Janeiro, Jorge Zahar Editor, 1997.

LIMA, A. Luzes para uma face no escuro: a emergência de uma rede de valorização da expressividade afroalagoana. Dissertação de mestrado defendida junto ao Programa de Pós-graduação em Sociologia da Universidade Federal de Alagoas. Ano de defesa: 2015. 
LINDOSO, Dirceu. A utopia armada: rebeliões de pobres nas matas do tombo real (1832-1850). Maceió: Edufal, 2005.

MAGALHÃES, L. F. B. G. Políticas culturais e políticas de identidade em Alagoas: governo Ronaldo Lessa (1999-2006) e governo Teotônio Vilela (2007-2014). Dissertação de mestrado defendida junto ao Programa de Pós-graduação em Sociologia da Universidade Federal de Alagoas. Ano da defesa: 2016.

POUTIGNAT, P. STREIFF-FERNART, J. Teorias da etnicidade. São Paulo: Unesp, 1997.

Recebido em 5 de dezembro de 2019. Aprovado em 19 de julho de 2020. 